九州大学学術情報リポジトリ

Kyushu University Institutional Repository

Effects of Previous Water Stress Treatment on the Leaf Photosynthesis and Related Factors in Oats (C_3) and Maize (C_4)

Miyazaki, Akira

Laboratory of Practical Botany, Faculty of Agriculture, Kyushu University

Kubota, Fumitake

Laboratory of Practical Botany, Faculty of Agriculture, Kyushu University

Agata, Waichi

Laboratory of Practical Botany, Faculty of Agriculture, Kyushu University

https://doi.org/10.5109/24069

出版情報: 九州大学大学院農学研究院紀要. 39 (1/2)，pp.67-77，1994-12. Kyushu University バージョン：

権利関係 : 
J. Fac. Agr., Kyushu Univ., $39(1 \cdot 2), 67-77$ (1994)

\title{
Effects of Previous Water Stress Treatment on the Leaf Photosynthesis and Related Factors in Oats $\left(\mathrm{C}_{3}\right)$ and Maize $\left(\mathrm{C}_{4}\right)$
}

\author{
Akira Miyazaki, Fumitake Kubota and Waichi Agata \\ Laboratory of Practical Botany, Faculty of Agriculture, \\ Kyushu University, Fukuoka 812, Japan. \\ (Received August 15, 1994)
}

\begin{abstract}
The acclimation effect of previous water stress on the photosynthetic characteristics was clarified using oats $\left(\mathrm{C}_{3}\right)$ and maize $\left(\mathrm{C}_{4}\right)$. On the plants previously water stressed (pretreatment), the leaf photosynthetic rate, stomatal response, water potential and the related factors were measured during the following water stress application (posttreatment) to be compared to those of non stressed (control) plants. The posttreatment was imposed to the plants by withholding water supply (Experiment 1, a lenient stress) or also by stem cut (experiment 2, a quick stress) The results obtained were as follows : Experiment 1. Oats which had been recovered from the previous water stress showed higher values for leaf photosynthetic rate, stomatal conductance and mesophyll conductance compared to the control when the plants were placed under the posttreatment. Also lower osmotic potential $\left(\Psi_{\pi}\right)$ and higher pressure potential $\left(\Psi_{\mathrm{p}}\right)$ were observed when the leaf water potential $\left(\Psi_{1}\right)$ of the pretreated Oats reduced. The osmotic adjustment was effective in maintaining leaf photosynthetic rate of oats but such an effect was not detected in maize. Experiment 2. A quick water stress (posttreatment) was applied to the plants, oats and maize, recovered from the previous stress. A similar osmotic adjustment to that observed in the experiment 1 was obtained for oats, but the pretreatment was ineffective or adversely effective for maintenance of $\psi_{\mathrm{D}}$ in maize.
\end{abstract}

\section{INTRODUCTION}

Water is an essential factor for the life preservation and production of plant. In a water stressed plant, the photosynthetic rate is restricted by stomatal closure due to the turgor pressure reduction in the guard cells and also by the inactivation of photosynthetic system in the chlorophyls. The plant, being subjected to severe water stress for a long time, can not survive. However, when the plant is placed under the not so strong water stress, so called mild water stress, the growth is temporarily limited but it can soon recover (Itoh and Kumura, 1986 and 1987 ; Nonami and Boyer, 1989 ; Pritchard et al., 1990). Many crops grown in the temperate zone are usually subjected to mild water stress, and therefore evaluating the crops concerning the drought tolerance or acclimation effect obtained under mild water stresses is useful as information for improving their productivity and cultivation system.

The phenomenon that drought tolerance is improved in a plant experienced water stress in advance has been studied from the physiological aspect for many plants. Higher photosynthetic rates and higher stomatal conductances were observed at low leaf water potentials in previously stressed $\mathrm{C}_{3}$ plants such as sunflower (Matthews and Boyer, 1984) and cotton (Brown et al., 1976 ; Ackerson and Hebert, 1981 ; Ackerson, 1981) than those of the previously non stressed plants. On the other hand, as Jones and 
Rawson (1979) reported, the pretreatment offered no effect on the photosynthetic rate, stomatal conductance and osmotic adjustment of sorghum $\left(\mathrm{C}_{4}\right.$ plant $)$ : the pretreatment does not always seem effective in improving the water stress tolerance. Effects of the previous stress on the plant production and photosynthesis are different with plants, and a unified conclusion concerning the effect of pretreatment of water stress has not been obtained yet.

Osmotic adjustment to drought is regarded as an important function responding to the water status in a plant : the accumulation of solute in a cell allows the maintenance of water absorption power by enlarging the gradient of osmotic pressure between inside and outside of the cell (Cutler and Rains, 1978 ; Inada et al., 1992 ; Turner et al., 1978).

In this study, the effect of previous water stress on the characteristics of leaf photosynthesis, stomatal conductance and mesophyll conductance are examined using oats $\left(\mathrm{C}_{3}\right)$ and maize $(\mathbf{C}$,$) . The relationships between the osmotic adjustment and these$ factors are discussed to clarify the acclimation effect obtained in the previous water stress and its difference between $\mathrm{C}_{3}$ and $\mathrm{C}_{4}$ plants.

\section{MATERIALS AND METHODS}

Oats $\left(\mathrm{C}_{3}\right.$, Avena sativa (L.) cv. Almighty) and maize ( $\mathrm{C}$, Zea mays (L.) cv. Pioneerdent 3352) were used as experimental materials. Seeds of oats and maize previously germinated on a wet filter paper at $30^{\circ} \mathrm{C}$ in the dark were sown in $10.5 \mathrm{~L}$-pot containing $7.5 \mathrm{~L}$-sandy soil fertilized at a level of $\mathrm{N}: \mathrm{P}_{2} \mathrm{O}_{5}: \mathrm{K}_{2} \mathrm{O}=8: 8: 8 \mathrm{~g} /$ pot. Three plants per pot were grown in a vinyl house set up in the experimental field of Kyushu University. The growth periods of oats and maize were from October in 1993 to the next January and from October to November in 1993, respectively. When the sixth leaf completely expanded in oats and the second leaf completely expanded in maize, the water stress treatment (pretreatment) was initiated by withholding water supply. Then just after the water potential of the top expanded leaf reduced to-2.0MPa in oats and to $-1.7 \mathrm{MPa}$ in maize, the pretreatment was terminated by rewatering the plants.

\section{Experiment 1}

After the pretreated plants were sufficiently rewatered, they were subjected again to the following water stress by water supply cut (posttreatment). Photosynthetic rate, stomatal conductance and mesophyll conductance of the pretreated plants were measured during the posttreatment and were compared to those of the control plants (previously non stressed plants). The treatment process is presented in Fig. 1.

Photosynthetic rate and its related factors were measured on the top expanded

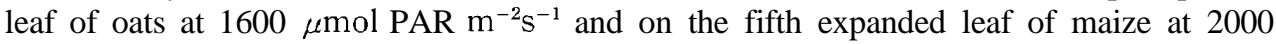
$\mu \mathrm{mol}$ PAR $\mathrm{m}^{-2} \mathrm{~s}^{-1}$ using a portable photosynthesis and evaporation system (SPB-H3, ADC, Britain) .

Leaf water potential was determined with a thermocouple psychrometer (C-52 sample chamber, Wescor, USA) . Leaf osmotic potential was measured according to a method of Premachandra et al. $(1991,1992)$ : the small leaf disc used for water potential measurement was placed in a $1.5 \mathrm{ml}$ eppendorf tube and frozen at $-85^{\circ} \mathrm{C}$, and 

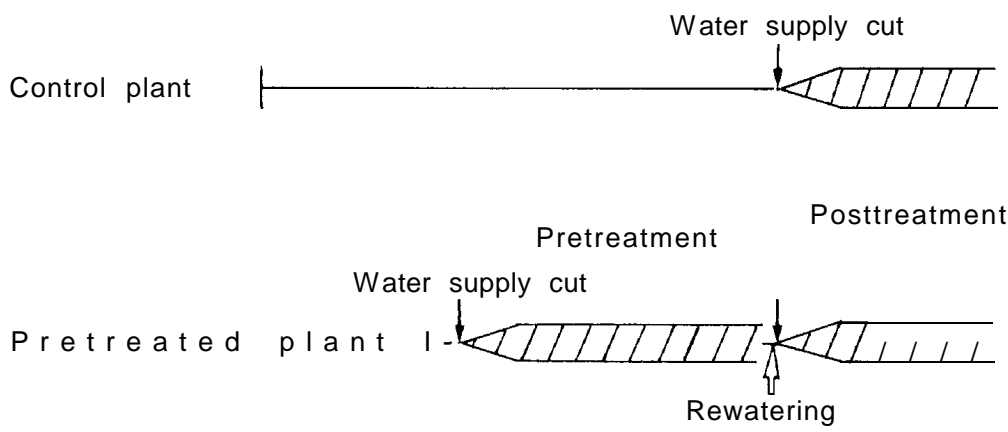

Fig. 1. The pretreatment and posttreatment process. When the water potential of top expanded leaf reduced to $-2.0 \mathrm{MPa}$ for oats and -1 . $7 \mathrm{MPa}$ for maize, the pretreatment was terminated by rewatering. After that, the plants were subjected to the following posttreatment. Photosynthesis and its related factors were measured during the posttreatment.

then it was defrosted at room temperature for 30 minutes to measure the osmotic potential with the thermocouple psychrometer. Pressure potential $\left(\Psi_{\mathrm{p}}\right)$ was determined as the difference between water potential $\left(\Psi_{1}\right)$ and osmotic potential $\left(\Psi_{\pi}\right)$. Five replications were made on each factor for the five control and five pretreated plants of each species.

\section{Experiment 2}

Water transport from roots to leaves can be stopped by cutting the stem of a plant, and by this treatment the leaves are subjected to a quick water stress. This quick water stress treatment was applied to the control and pretreated plants in oats and maize both of which were sufficiently rewatered after pretreatment termination. Both $\Psi_{1}$ and $\Psi_{\pi}$ were measured in time course, and $\Psi_{\mathrm{P}}$ was calculated from $\Psi_{1}$ and $\Psi_{\pi}$.

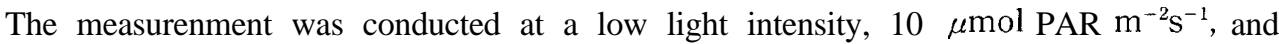
temperature was set to 25 and $30^{\circ} \mathrm{C}$ for oats and maize, respectively. Measurements on these factors were replicated three times using the six control and six pretreated plants of each species.

\section{RESULTS}

\section{Experiment 1}

Effects of leaf water potential $\left(\Psi_{1}\right)$ depression on photosynthetic rate, stomata1 conductance and mesophyll conductance

Figure 2 shows the change in photosynthetic rate, stomatal conductance and mesophyll conductance with decreasing $\Psi_{1}$ in oats. Photosynthetic rate in both control and pretreated plants decreased with decreasing $\Psi_{1}$. A distinctive treatment effect was detected in photosynthetic rate at -0.7 to $-1.0 \mathrm{MPa} \Psi_{1}$ : photosynthetic 

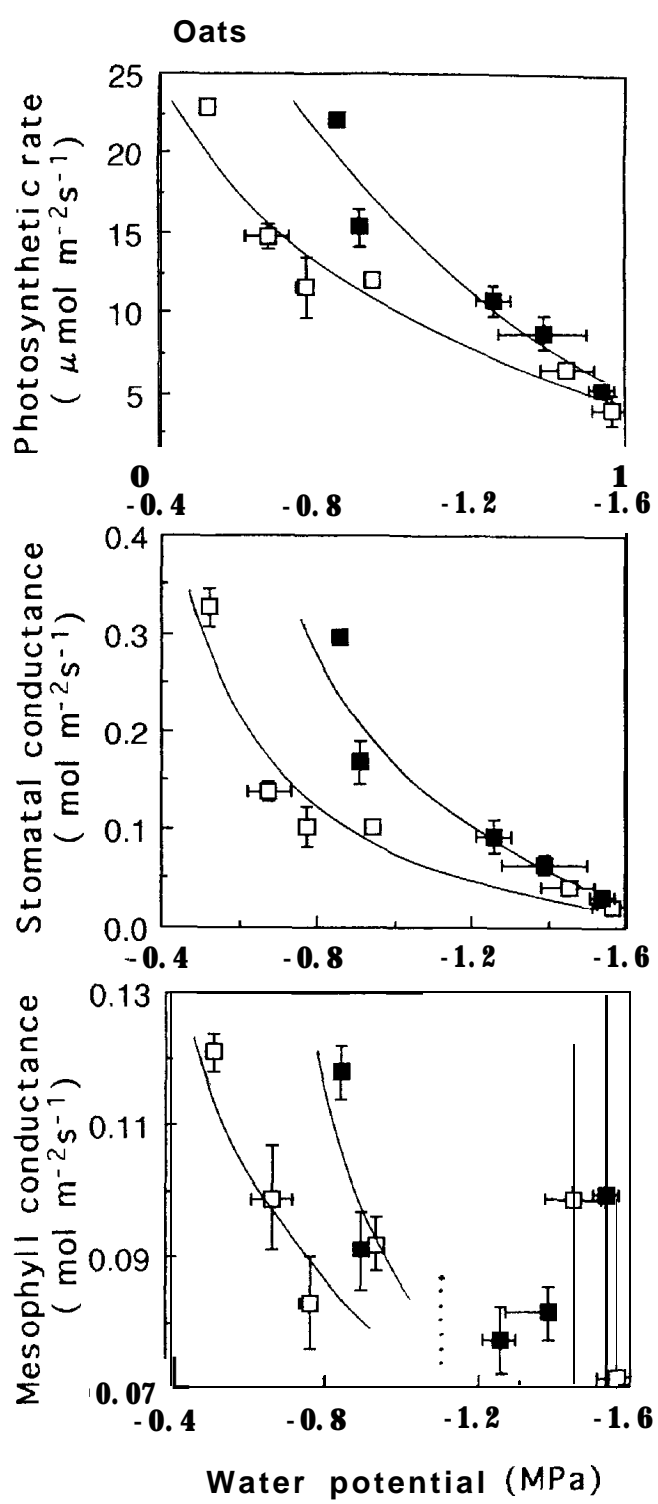

Fig. 2. The effect of decreasing leaf water potential on photosynthetic rate, stomatal conductance, and mesophyll conductance of control $(\square)$ and pretreated ( $\square$ ) leaves in oats. The horizontal and vertical bars indicate standard errors of the mean. 
rate of the pretreated plants was 15 to $22 \mu \mathrm{molm} \mathrm{m}^{-2} \mathrm{~s}^{-1}$ at $-0.9 \mathrm{MPa} \Psi_{1}$, which was 1 . 3 to 1.8 times higher than that of the control plants. However, the difference in photosynthetic rate became indistinctive as $\Psi_{1}$ decreased below $-1.2 \mathrm{MPa}$. The pretreated plants showed higher photosynthetic rates and higher stomatal conductances than those of the control plants. Although mesophyll conductance measured at less than $-1.4 \mathrm{MPa} \Psi_{1}$ presented a large deviation, the pretreated plants maintained a higher mesophyll conductance than the control plants at more than $-1.0 \mathrm{MPa} \Psi_{1}$ at which a clear difference of treatment effect was shown in photosynthetic rate.

Figure 3 shows the change in photosynthetic rate, stomatal conductance and mesophyll conductance with $\Psi_{1}$ in maize. These three factors decreased linearly with a decrease in $\Psi_{1}$ and there were no differences in treatment effect on these measurements between control and pretreated plants.

\section{Interrelationships between photosynthetic rate, stomatal conductance and meso- phyll conductance}

Photosynthetic reduction observed in a water stressed plant is mainly caused by stomatal closure by which $\mathrm{CO}$, supply from the air into the leaf is restricted and also caused by enzymatic inactivation in photosynthetic system in the chlorophyls. The photosynthetic activity in chlorophyls is indicated as mesophyll conductance which shows a $\mathrm{CO}$, traveling efficiency from substomatal cavity to photosynthetic operation site of chlorophyls. In order to know the effect of both stomata1 and mesophyll conductances on the leaf photosynthetic rate of a plant under water stress conditions, the relationships between photosynthetic rate and stomatal conductance, and mesophyll conductance are shown in Fig. 4. Photosynthetic rates of oats and maize decreased with decreasing stomatal conductance, and there was no difference in the treatment effect on this relationship for both species. Also the treatment effect on the relationship between photosynthetic rate and mesophyll conductance was negligible.

\section{Relationships between water potential $\left(\Psi_{1}\right)$, osmotic potential $\left(\Psi_{\pi}\right)$ and pressure potential $\left(\Psi_{\mathrm{p}}\right)$ in a leaf}

Figure 5 shows the relationships between $\Psi_{1}$ and $\Psi_{\pi}$, and $\Psi_{\mathrm{p}}$ in oats. The values of $\Psi_{\pi}$ and $\Psi_{\mathrm{p}}$ in both control and pretreated plants decreased as $\Psi_{1}$ decreased, and $\Psi_{\pi}$ of the pretreated plants was lower than that of the control plants while $\Psi_{\mathrm{p}}$ of the pretreated plants was higher by 0.08 to $0.24 \mathrm{MPa}$ than that of the control plants.

The relationships between $\Psi_{1}$ and $\Psi_{\pi}$, and $\Psi_{\mathrm{p}}$ in maize can be seen in Fig. 6. Both $\Psi_{\pi}$ and $\Psi_{\mathrm{p}}$ decreased linearly with decreasing $\Psi_{1}$ in the control and pretreated plants, and these relationships were not different between the plants which had been subjected to the pretreatment or not.

\section{Experiment 2}

Time course of osmotic potential $\left(\Psi_{\pi}\right)$ and pressure potential $\left(\Psi_{\mathrm{p}}\right)$ under the quick water stress

If the time interval from the pretreatment termination to the posttreatment initiation is long, the acclimation effect obtained during the previous water stress may be reduced. In this experiment, the soil volume $(7.5 \mathrm{~L})$ in a pot is not so small, so that the application of water stress to plants by withholding water supply is lenient. After 

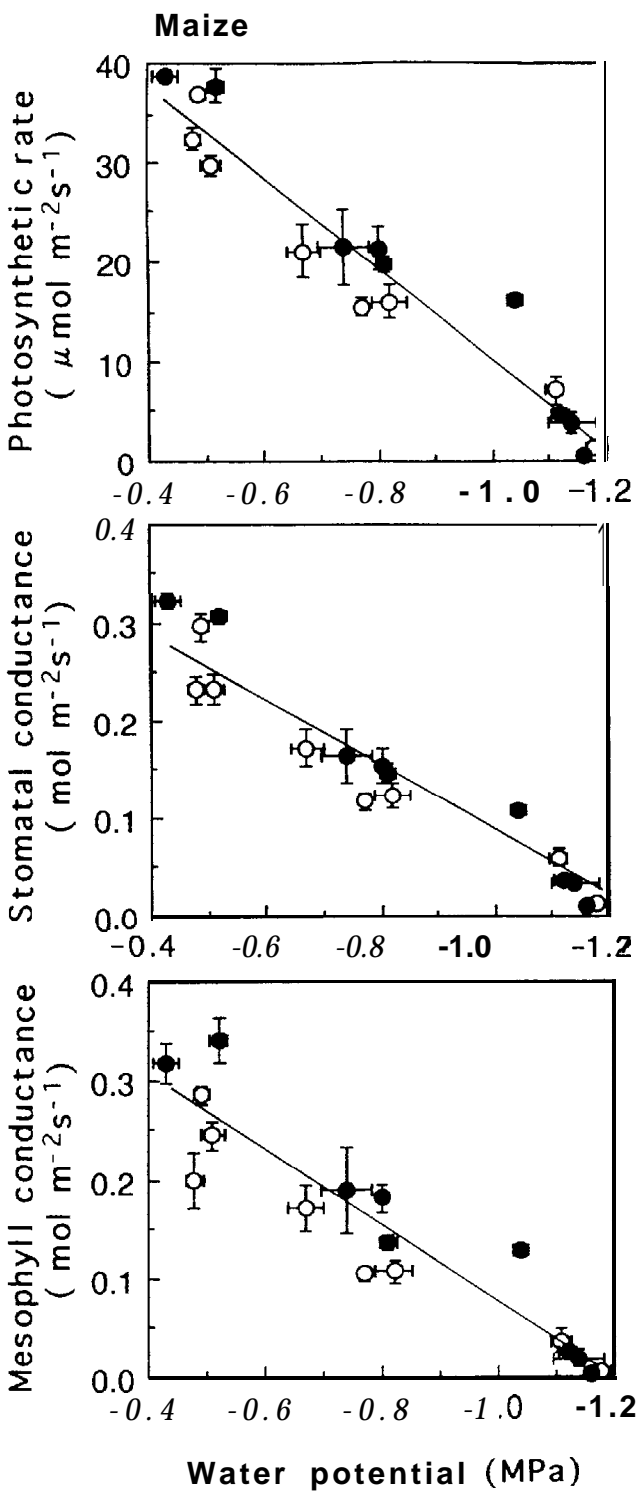

Fig. 3. The effect of decreacing leaf water potential on photosynthetic rate, stomatal conductance, and mesophyll conductance of control $(\bigcirc)$ and pretreated $(\mathbf{O})$ leaves in maize. The horizontal and vertical bars indicate standard errors of the mean. 

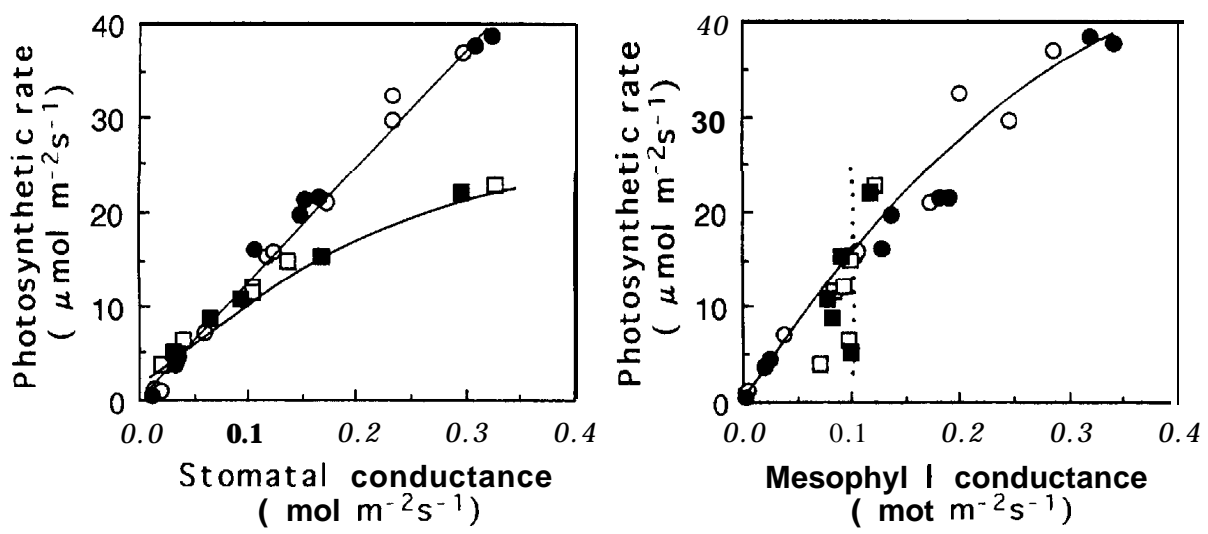

Fig. 4. Relationships between photosynthetic rate and stomatal conductance, mesophyll conductance of control (oats: $\square$, maize : $\bigcirc$ ) and pretreated (oats: $\square$, maize : plants.
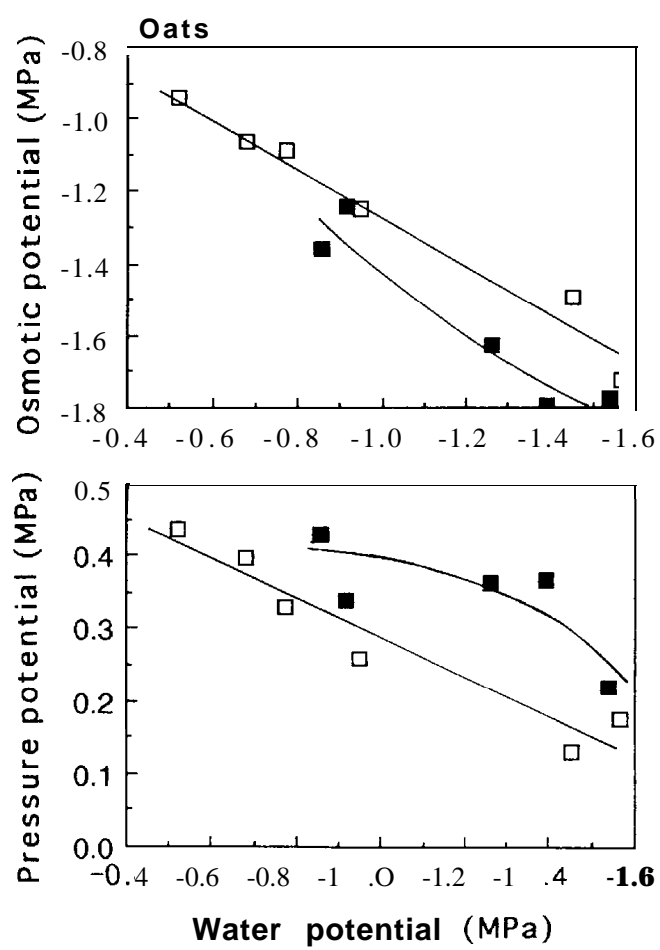

Fig. 5. The effect of leaf water potential reduction on osmotic potential and pressure potential of control $(\square)$ and pretreated (ם) leaves in oats. 

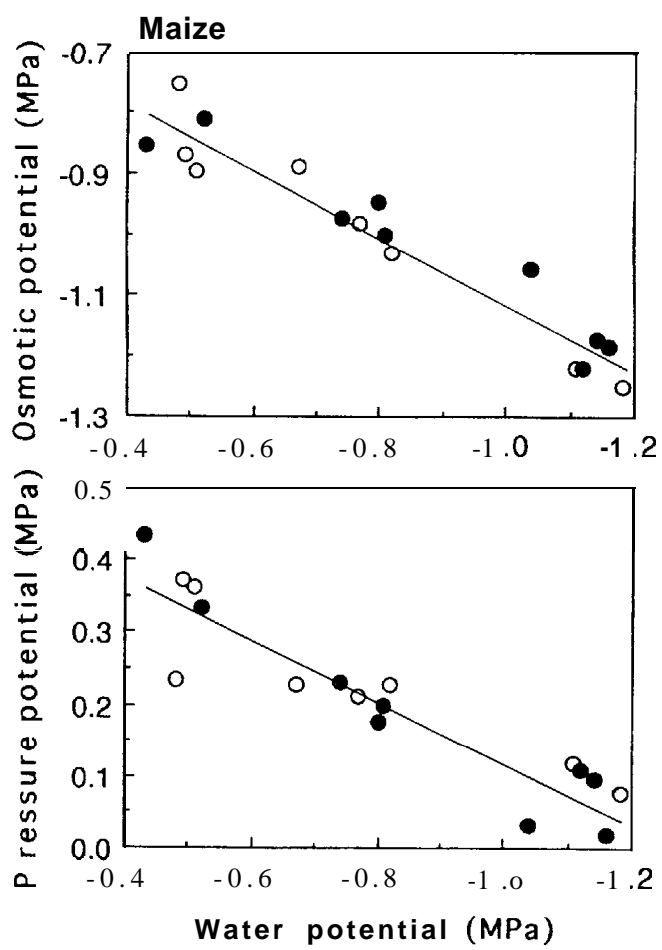

Fig. 6. The effect of leaf water potential reduction on osmotic potential and pressure potential of control $(O)$ and pretreated (O) leaves in maize.

the posttreatment initiation, a plant might begin to acclimate to the drought condition of the posttreatment and providing that the acclimation effect obtained in the pretreatment is influenced and changed by that of the posttreatment. Application of a quick water stress in the posttreatment is a method to avoid the mixing of the pretreatment and posttreatment effects.

In this experiment, the stem of a plant which had recovered from the previous water stress was cut at the ground surface level to give a quick water stress to the leaves, and the time courses of $\Psi_{1}, \Psi_{\pi}$ and $\Psi_{\mathrm{p}}$ were determined. Fig. 7 shows the changes in $\Psi_{\pi}$ and $\Psi_{\mathrm{p}}$ with time after stem cutting in oats and maize. In oats, $\Psi_{\pi}$ of both control and pretreated plants varied at a similar decreasing rate with time, but $\Psi_{\pi}$ of the pretreated plants was about $0.2 \mathrm{MPa}$ lower than that of the control plants. Also the pretreated plants had a higher $\Psi_{\mathrm{p}}$ than the control plants. On the other hand, in maize, there was almost no difference in $\Psi_{\pi}$ between the treatments, and $\Psi_{\mathrm{p}}$ of the pretreated plants decreased more quickly with time than that of the control plants. 

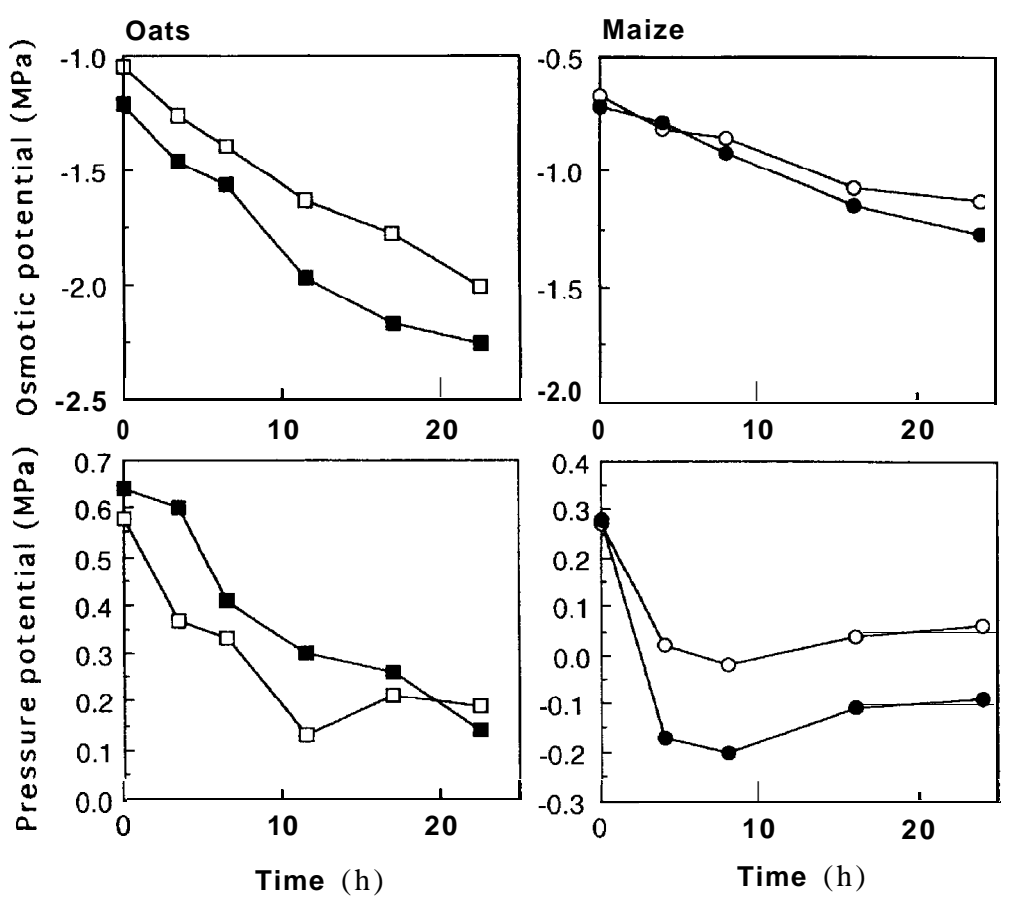

Fig. 7. Time course of osmotic potential and pressure potential of control (oats: $\square$, maize: $\bigcirc$ ) and pretreated (oats: $\square$, maize : $)$ plants after stem cut treatment.

\section{DISCUSSION}

It has been reported that many plants such as cotton (Ackerson and Hebert, 1981), spinach (Santakumari and Berkowitz, 1991), sunflower (Matthews and Boyer, 1984) which had experienced water stress in advance showed higher photosynthetic rates at low $\Psi_{1}$. In their experiments, the photosynthetic rate of the pretreated plants was about $60 \%$ higher at -1.4 to $-1.8 \mathrm{MPa} \Psi_{1}$ for cotton, and it was about $30 \%$ higher at -1.0 to $-1.5 \mathrm{MPa} \Psi_{1}$ for spinach and about $50 \%$ higher at -1.0 to $-2.0 \mathrm{MPa} \Psi_{1}$ for sunflower in comparison with that of the control plants.

Oats (C,) used here had a 21 to $45 \%$ higher photosynthetic rate at -0.7 to -1 . $0 \mathrm{MPa} \Psi_{1}$ than that of the control plants. The effect of previous water stress can be seen not only on photosynthetic rate but also on stomatal and mesophyll conductances. However, there was no effect on the relationships between photosynthetic rate and stomata1 conductance, and mesophyll conductance (Fig. 4) .

By dividing $\Psi_{1}$ into two factors, $\Psi_{\pi}$ and $\Psi_{\mathrm{p}}$, we can know the acclimation effect of the osmotic adjustment and turgor pressure on the photosynthetic rate. The occurrence of osmotic adjustment in the pretreated oats may be identified from the 
fact that $\Psi_{\pi}$ was lower and $\Psi_{\mathrm{p}}$ was higher in the pretreated plants than those of the control plants (Fig. 5) . Since $\Psi_{\pi}$ of the pretreated plants was lower at high $\Psi_{\mathrm{p}}$ than that of the control plants, it may be predicted that solutes accumulated in a leaf during the pretreatment was not lost until the following stress treatment. The fact, that the variation gradient of $\Psi_{\pi}$ to $\Psi_{1}$ was not different between control and pretreated plants, may indicate that the solute accumulation ability of oats was not improved by the pretreatment.

On the other hand, the osmotic adjustment of maize was not affected by the pretreatment : the decreasing rates of $\Psi_{\pi}$ and $\Psi_{\mathrm{p}}$ with decreasing $\Psi_{1}$ were not different between control and pretreated plants, and this may suggest that the osmotic adjustment was not created by the stress experience in this species (Fig. 6) . There seems to be no acclimation effects on the photosynthetic rate, stomatal conductance and mesophyll conductance in maize (Fig. 3) .

The acclimation effect on photosynthetic characteristics may be changed with treatment conditions such as duration or strength of water stress and recovering time after pretreatment termination. Jones and Rawson (1979) noted that the period during which the water stress experienced plants maintained the acclimation effect was limited to less than a week. Also Turner and Jones (1980) demonstrated that the obtained osmotic adjustment ability remained for only several days and the effective adjustment was shown only in a limited range of water potential. In our experiment, it took 6 to 10 days until the photosynthetic rates of both species began to be restricted by water stress after the posttreatment initiation. There is a possibility that the acclimation effect obtained in the previous treatment was gradually reduced during this period. Jones and Rawson (1979) further reported that in the plants slowly subjected to the water stress, the photosynthesis and stomatal function were less sensitive to the decrease of $\Psi_{1}$ compared to the case that the plants was exposed to a quick water stress treatment.

Because the acclimation effect may be varied by the stress application period and strength as mentioned, a quick water stress imposition to a plant is a method to obtain more accurate evaluation of acclimation. Here we applied a quick stress to the plants by stem cutting and then determined the changes in $\Psi_{\pi}$ and $\Psi_{\mathrm{p}}$ with time. The time courses of these two factors showed clearly different responses between oats and maize. The results for oats were similar to those showed in the experiment 1 : the solute accumulation during the pretreatment is suggested to play an important role in osmotic adjustment because $\Psi_{\pi}$ was lower and $\Psi_{\mathrm{p}}$ was higher in the pretreated plants than in the control plants (Fig. 7) . On the other hand, it may be predicted for maize that the water loss by evaporation after the stem cut was greater in the pretreated plants because $\Psi_{\mathrm{p}}$ of the pretreated plants was lower than that of the control plants.

From the results of the experiments 1 and 2, it is concluded that the pretreatment is effective in maintaining the photosynthetic ability of oats but ineffective or adversely effetive for maize. The water stress responses observed on both species oats $\left(\mathrm{C}_{3}\right)$ and maize $(\mathrm{C}$,$) used here showed good agreement with the results reported on sun-$ flower $\left(\mathrm{C}_{3}\right)$, spinach $\left(\mathrm{C}_{3}\right)$, cotton $\left(\mathrm{C}_{3}\right)$ and sorghum $\left(\mathrm{C}_{4}\right)$. This fact may suggest that the different responses in osmotic adjustment or acclimation to water stress between oats and maize probably depended on the different photosynthetic systems of $\mathrm{C}_{3}$ and $\mathrm{C}_{4}$ plants, but to get a concrete conclusion about this phenomenon, more detailed 
studies are necessary using many $\mathrm{C}_{3}$ and $\mathrm{C}_{4}$ plants.

\section{REFERENCES}

Ackerson, R. C. and R. R. Hebert 1981 Osmoregulation in cotton in response to water stress. I . Alterations in photosynthesis, leaf conductance, translocation, and ultrastructure. Plant Physiol., $67: 484-488$

Ackerson, R. C. 1981 Osmoregulation in cotton in response to water stress, II. Leaf carbohydrate status in relation to osmotic adjustment. Plant Physiol., 67: 489-493

Brown, K. W., W. R. Jordan and J. C. Thomas 1976 Water stress induced alterations of the stomata1 response to decreases in leaf water potentials. Physiol. Plant., 37: 1-5

Cutler, J. M. and D. W. Rains 1978 Effects of water stress and hardening on the internal water relations and osmotic constituents of cotton leaves. Physiol. Plant., $42: 261-268$

Inada, K., A. Matsuura and M. Yamane 1992 Interspecific differences in the mechanism of drought tolerance among four cereal crops. Japan. J. Crop Sci., 61 (1) : 87-95

Itoh, R. and A. Kumura 1986 Acclimation of soybean plants to water deficit. I. Effects of prolonged water deficit on the production and partition of dry matter. Japan. J. Crop Sci., 55 (3) : 367-373

Itoh, R. and A. Kumura 1987 Acclimation of soybean plants to water deficit. III. Change in leaf growth as regulated by "leaf extensibility" and pressure potential under various soil water regimes. Japan. J. Crop Sci., 56 (1) : 109-114

Jones, M. M. and H. M. Rawson 1979 Influence of rate of development of leaf water deficits upon photosynthesis, leaf conductance, water use efficiency and osmotic potential in sorghum. Physiol. Plant., 45 : 103-111

Matthews, M. A. and J. S. Boyer 1984 Acclimation of photosynthesis to low leaf water potentials. Plant. Physiol., 74: 161-166

Nonami, H. and J. S. Boyer 1989 Turgor and growth at low water potentials. Plant Physiol., 89: 798-804

Premachandra, G. S., H. Saneoka, K. Fujita and S. Ogata 1992 Leaf water relations, osmotic adjustment, cell membrane stability, epicuticular wax load and growth as affected by increasing water deficits in sorghum. J. Exp. Bot., $43: 1569-1576$

Premachandra, G. S., H. Saneoka and S. Ogata 1991 Cell membrane stability and leaf water relations as affected by potassium nutrition of water stressed maize. J. Exp. Bot., 42: 739-745

Pritchard, J., R. G. Wyn Jones and A. D. Tomos 1990 Measurement of yield threshold and cell wall extensibility of intact wheat roots under different ionic, osmotic and temperature treatments. J. Exp. Bot., 41: 669-675

Santakumari, M. and G. A. Berkowitz 1991 Chloroplast volume : cell water potential relationships and acclimation of photosynthesis to leaf water deficits. Photosynthesis Research., 28 : 9-20

Turner, N. C., J. E. Begg and M. L. Tonnet 1978 Osmotic Adjustment of sorghum and sunflower crops in response to water deficits and its influence on the water potentials at which stomata close. Aust. J. Plant Physiol., 5: 597-608

Turner, N. C. and M. M. Jones 1980 Turgor maintenance by osmotic adjustment : A review and evaluation. In "Adaptation of plants to water and high temperature stress", ed. by N. C. Turner and P. J. Kramer, Wiley, New York., pp. 87-103 